\title{
Lead and Cadmium Immobilization by Polymeric Sponges Coated with Hydroxyapatite
}

\author{
E. Mavropoulos ${ }^{1, a}$, N. C. C. da Rocha, ${ }^{2, b}$, M. L. F. M. Kede ${ }^{3, c}$, \\ M. H. Prado da Silva, d, J. C. Moreira ${ }^{3, e}$ and A M. Rossi ${ }^{1, f}$ \\ ${ }^{1}$ CBPF, R. Dr Xavier Sigaud 150, Urca, CEP 22290-180, RJ, Brazil \\ ${ }^{2}$ UFRJ/IQ/DQA, Cidade Universitária, C T, Bloco A/517, CEP 21941-590, RJ, Brazil \\ ${ }^{3}$ Fundação Oswaldo Cruz, R. Leopoldo Bulhões 1480, CEP 21041-210, RJ, Brazil \\ ${ }^{4}$ Instituto Militar de Engenharia, Praça General Tiburcio 80, CEP 22290-270, RJ, Brazil \\ aelena@cbpf.br, ${ }^{\mathrm{b}} \mathrm{carbonel@iq.ufrj.br,}{ }^{\mathrm{C}}$ luiza.kede@ensp.fiocruz.br, ${ }^{\mathrm{d}}$ marceloprado@ime.eb.br, \\ josinocm@fiocruz.br, ${ }^{f}$ rossi@cbpf.br
}

Keywords: hydroxyapatite, monetite, lead, cadmium

\begin{abstract}
Polymeric sponges coated with hydroxyapatite were used in lead and cadmium uptake experiments in order to mimetizes heavy metal incorporation by bone tissue. The hydroxyapatitecoated sponges (S-HA) were obtained by hydrothermal alkali conversion from monetite. The results showed that $\mathrm{S}$-HA were efficient in immobilizing $\mathrm{Pb}$ and $\mathrm{Cd}$. The uptake experiments using hydroxyapatite powder (HA) removed almost $100 \%$ of $\mathrm{Pb}^{2+}$ and $59 \%$ of $\mathrm{Cd}^{2+}$. When polymeric sponges coated with hydroxyapatite were used, the removal of $\mathrm{Cd}^{2+}$ and $\mathrm{Pb}^{2+}$ decreased, respectively, to closely $14 \%$ and $74 \%$, after 24 hours sorption. Before and after sorption experiment MEV analysis indicated precipitation of pyromorphite on hydroxyapatite-coated sponges.
\end{abstract}

\section{Introduction}

Lead and cadmium are considered toxic to human being and can affect almost all organs. Once absorbed, these metals are found in body's hard tissues such as bones and teeth. Hydroxyapatite is one of the main constituents of bone inorganic phase and in addition, synthetic hydroxyapatite shows very high capacity in adsorb heavy metals from water $[1,2]$. This property allows studies in metal incorporation by bone.

In this work, studies were developed to assess lead and cadmium immobilization by apatite scaffolds produced by a patented technique [3] that resemble trabecular bone. The aim of this study is to investigate the efficiency of HA scaffolds in immobilizing heavy metals.

\section{Materials and Methods}

\section{Samples Preparation}

Synthetic hydroxyapatite powder, HA, was synthesized by drop wise addition of an $\left(\mathrm{NH}_{4}\right)_{2} \mathrm{HPO}_{4}$ aqueous solution to a $\mathrm{Ca}\left(\mathrm{NO}_{3}\right)_{2}$ solution (PA Merck) at $80^{\circ} \mathrm{C}$ and $\mathrm{pH}=11$. It was a pure $\mathrm{HA}$ with a $\mathrm{Ca} / \mathrm{P}$ molar ratio of $1.65 \pm 0.03$ and surface area BET of $45 \pm 4 \mathrm{~m}^{2} \mathrm{~g}^{-1}$.

The apatite scaffolds, S-HA, were produced by hydrothermal coating of polymeric sponges with monetite, using a solution rich in $\mathrm{Ca}^{2+}$ and $\mathrm{PO}_{4}{ }^{3-}$ ions, according to the technique described in [3]. The conversion of monetite to HA was accomplished submerging the coated sponges in $0.5 \mathrm{M}$ $\mathrm{NaOH}$ aqueous solution at $80^{\circ} \mathrm{C}$ for 48 hours $[3,4]$.

\section{Sample Characterization}

HA powder and apatite scaffolds were analyzed by a SEIFERT-FPM GmbH X-ray diffractometer (XRD) operating with $\mathrm{CuK \alpha}$ radiation $(1.5418 \AA$ ) at $40 \mathrm{kV}$ and $40 \mathrm{~mA}$ with a graphite monochromator in the primary bunch. The XRD patterns were obtained in an interval from 
10 to $100^{\circ}$ with $2 \theta$ step of $0.02^{\circ}$. Elementary chemical analysis of $\mathrm{Ca}^{2+}, \mathrm{P}^{2} \mathrm{~Pb}^{2+}$ and $\mathrm{Cd}^{2+}$ content were performed by ICP-OES using OPTIMA 3000 PERKIN-ELMER equipment.

A scanning electron microscope (SEM, LEICA, model S440) with disperse energy spectrometer (EDS) was used to assess phases morphology. Backscattered electron (BSE) and secondary electron (SE) contrast were used as complementary techniques to identify $\mathrm{Pb}^{2+}$-rich phases.

\section{Dissolution Experiments}

Dissolution experiments were performed using $40 \mathrm{~mL}$ of Milli-Q water containing $0.4 \mathrm{~g}$ of HA powder and S-HA. The slurry was mechanically shaken for 24 hours at $25^{\circ} \mathrm{C}$. Aliquots of the solution were collected at 1, 6 and 24 hours. HA slurry was centrifuged and filtered through a Durapore membrane (Millipore). The solution from sponge experiments was only filtrated. Ca and $\mathrm{P}$ concentrations were determined by Perkin Elmer ICP-OES OPTIMA 3000 spectrometer. All experiments were performed in triplicate.

\section{Sorption Experiments}

The uptake experiments using HA and S-HA were performed in triplicate using $0.4 \mathrm{~g}$ of each sample. Aqueous solution containing $450 \mathrm{mg} \cdot \mathrm{L}^{-1} \mathrm{Cd}^{2+}$ and $460 \mathrm{mg} . \mathrm{L}^{-1} \mathrm{~Pb}^{2+}$, respectively, were obtained from $\mathrm{Pb}\left(\mathrm{NO}_{3}\right)_{2}$ and $\mathrm{Cd}\left(\mathrm{NO}_{3}\right)_{2} \cdot 4 \mathrm{H}_{2} \mathrm{O}$. Each material was mechanically shaken with $40 \mathrm{~mL}$ of the solution up to 1, 6 and 24 hours. Following the uptake the samples were centrifuged and the supernatants were filtered using a $0.22 \mu \mathrm{m}$ membrane Millipore, diluted with $\mathrm{HNO}_{3} 0.25 \%$ and then analyzed by ICP. The solid residues were dried at $80^{\circ} \mathrm{C}$ and analyzed by XRD and SEM.

\section{Results and Discussion}

\section{Sample Characterization}

Figure 1a and $\mathrm{b}$ show the XRD patterns of polymeric sponges coated with monetite before and after conversion to hydroxyapatite. The presence of a small monetite peak on S-HA scaffold indicated that almost all monetite was converted to a crystalline hydroxyapatite.
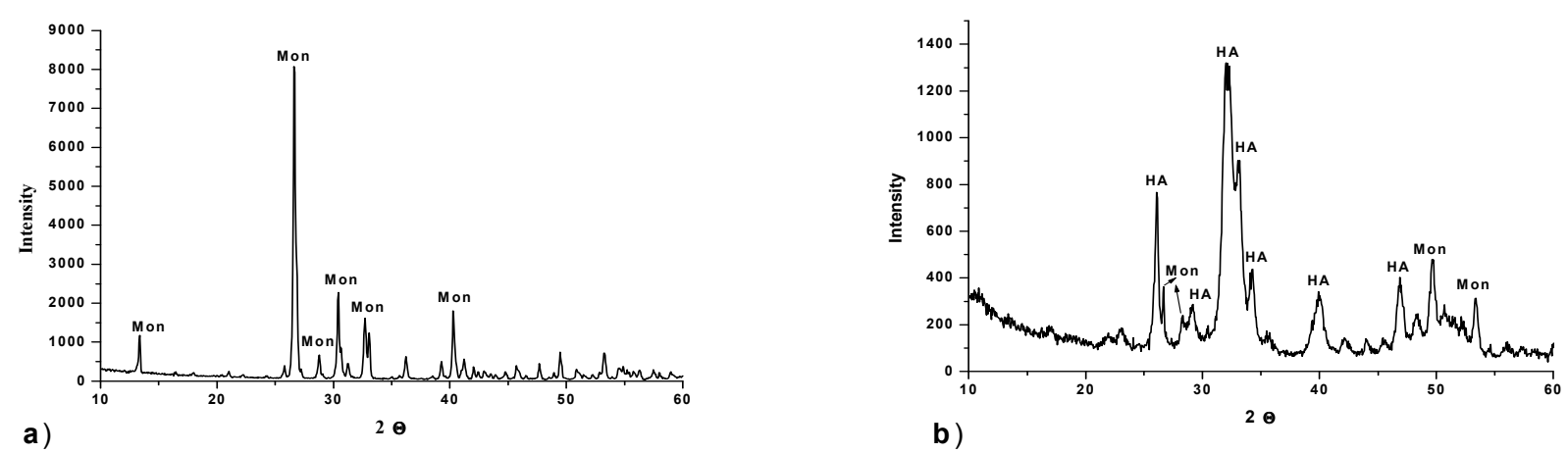

Figure 1: XRD pattern of polymeric sponges coated with monetite before (a) and after (b) conversion to S-HA.

\section{Dissolution Experiments}

Dissolution of $\mathrm{Ca}$ and $\mathrm{P}$ by HA and S-HA in Milli-Q water showed that both samples presented non stoichiometric dissolution. Chemical analyses revealed that after 24 hours, the $\mathrm{Ca}^{2+}$ concentration from HA powder and S-HA were nearly the same: $4.34 \times 10^{-5} \pm 2.99 \times 10^{-7} \mathrm{molL}^{-1}$ (HA) and $4.16 \times 10^{-5} \pm 2.99 \times 10^{-7} \mathrm{molL}^{-1}(\mathrm{~S}-\mathrm{HA})$. P concentration ranged from $7.35 \times 10^{-5} \pm 4.41 \times$ $10^{-6} \mathrm{molL}^{-1}$ (HA) to $1.06 \times 10^{-3} \pm 3.22 \times 10^{-4} \mathrm{molL}^{-1}$ (S-HA). The higher P dissolution of sample S- 
HA could be explained by the presence of small amount of monetite that still remains in polymeric sponges after conversion.

\section{Sorption Experiments}

HA powder immobilized $44 \mathrm{mg} / \mathrm{g}(100 \%)$ of $\mathrm{Pb}^{2+}$ and $26 \mathrm{mg} / \mathrm{g}(59 \%)$ of $\mathrm{Cd}^{2+}$, from a solution containing $460 \mathrm{mg} . \mathrm{L}^{-1}$ of $\mathrm{Pb}^{2+}$ and $450 \mathrm{mg} . \mathrm{L}^{-1} \mathrm{Cd}^{2+}$, Fig. $2 \mathrm{a}$. The experiment showed that 1

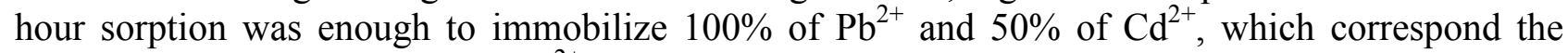
maximum sorption capacity for $\mathrm{Cd}^{2+}$ in these conditions [1].
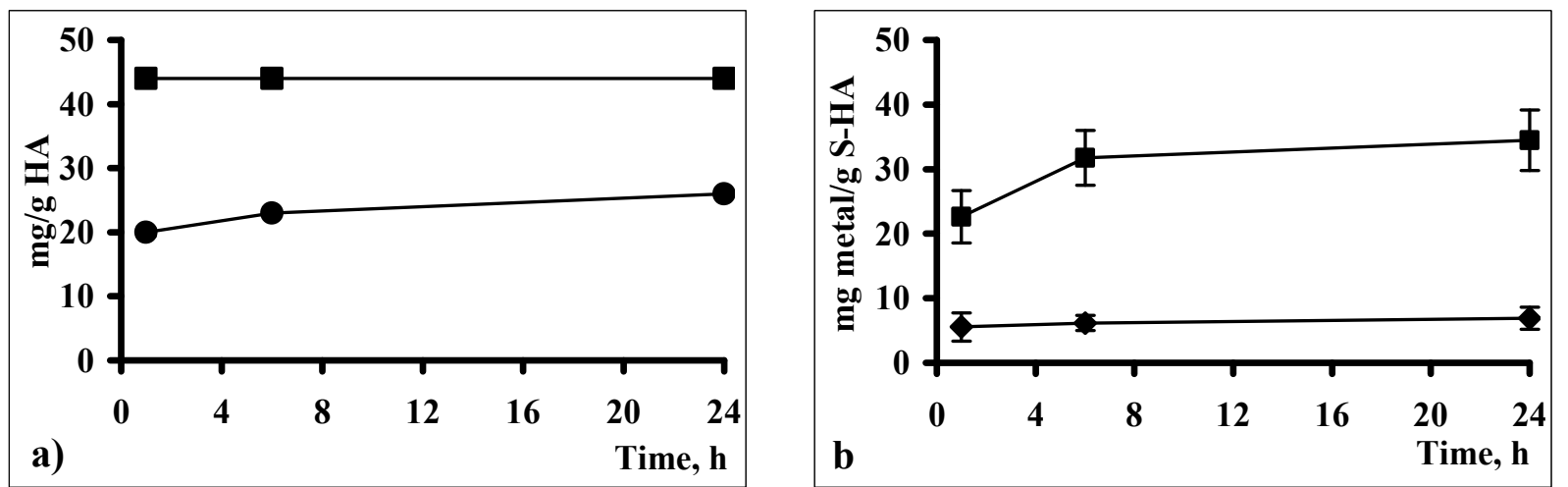

Figure 2: $\mathrm{Pb}^{2+}(\boldsymbol{\bullet})$ and $\mathrm{Cd}^{2+}(\bullet)$ uptake from HA (a) and S-HA (b). Initial concentration: 460 mg. $\mathrm{L}^{-1}$ of $\mathrm{Pb}^{2+}$ and $450 \mathrm{mg} \cdot \mathrm{L}^{-1} \mathrm{Cd}^{2+}$.

Sorption experiments using polymeric sponges coated with HA (S-HA) showed that the sorption of $\mathrm{Cd}^{2+}$ was about $6.0 \mathrm{mg} / \mathrm{g}(14 \%)$ during all experiment which correspond the maximum capacity sorption. After 24 hours $34 \mathrm{mg} / \mathrm{g}(74 \%) \mathrm{of} \mathrm{Pb}^{2+}$ was immobilized that represents six times the $\mathrm{Cd}^{2+}$ uptake (Fig. 2b). This result revealed that both materials HA and S-HA were efficient in immobilizing $\mathrm{Pb}^{2+}$ and $\mathrm{Cd}^{2+}$.

The main mechanism of $\mathrm{Pb}^{2+}$ immobilization depends on the amount of $\mathrm{P}$ available to form pyromorphite $[5,6]$. In this respect, S-HA dissolution released more $\mathrm{P}$ then HA, which could explain the pyromorphite formation observed to S-HA (Fig.3). No additional cadmium phosphate was detected in XRD pattern after $\mathrm{Cd}^{2+}$ adsorption indicating that $\mathrm{Cd}^{2+}$ immobilization was controlled by mechanisms such as ion exchange and surface complexation [7]. Therefore a competition to immobilize $\mathrm{Pb}^{2+}$ and $\mathrm{Cd}^{2+}$ on hydroxyapatite surface should occur when both metals occurred in a solution.

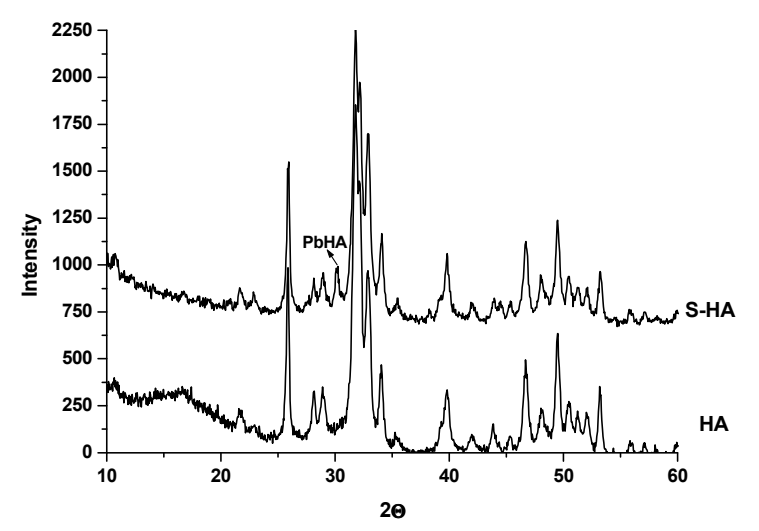

Figure 3. XRD patterns of HA and S-HA, showing pyromorphite formation on S-HA sample.

The SEM analyses of the polymeric sponges coated with HA, before and after sorption experiment are shown in Fig.4a and b. SEM analysis of the S-HA samples after incubation in the 
$\mathrm{Pb}$-Cd solution (Fig.4b) using secondary electrons contrast indicated the presence of $\mathrm{Pb}$-precipitates on the surface confirming pyromorphite precipitation.
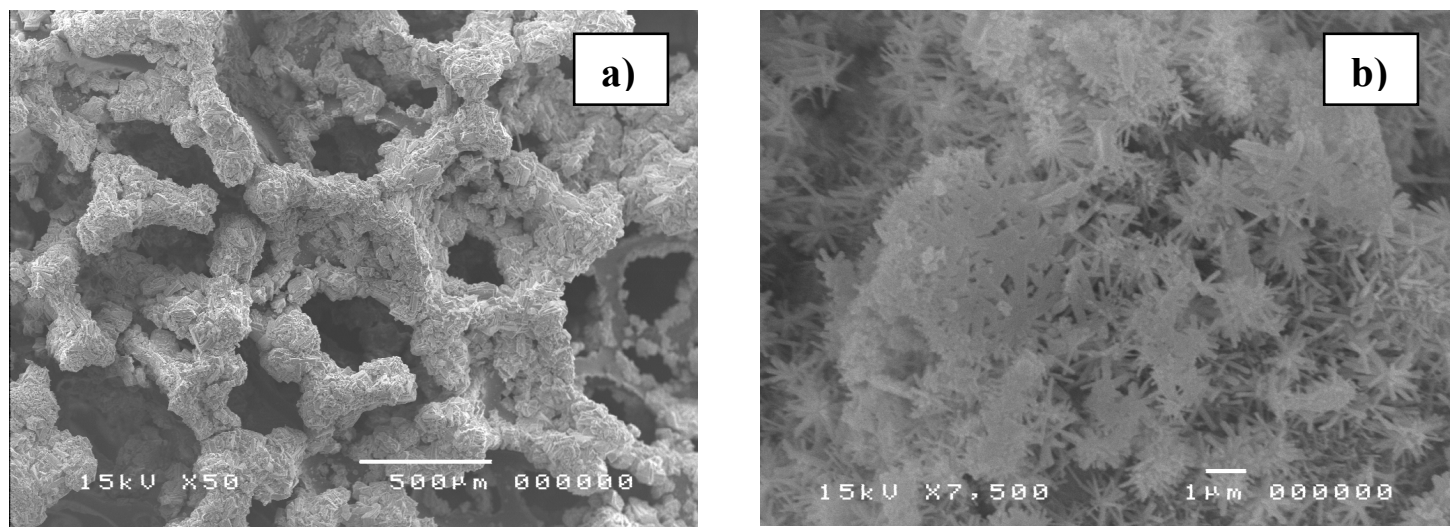

Figure 4: S-HA before (a) and after (b) $\mathrm{Pb}^{2+}$ and $\mathrm{Cd}^{2+} 24$ hour adsorption with $460 \mathrm{mg}$. $\mathrm{L}^{-1}$ of $\mathrm{Pb}^{2+}$ and $450 \mathrm{mg} \cdot \mathrm{L}^{-1} \mathrm{Cd}^{2+}$.

\section{Conclusions}

These results suggest that HA powder and polymeric sponges coated with hydroxyapatite were efficient to immobilize $\mathrm{Pb}^{2+}$ and $\mathrm{Cd}^{2+}$. The main mechanism involved in $\mathrm{Cd}^{2+}$ and $\mathrm{Pb}^{2+}$ immobilization for S-HA was respectively ion exchange and surface complexation $(\mathrm{Cd})$ and dissolution/precipitation process leading to a pyromorphite formation $(\mathrm{Pb})$.

\section{Acknowledgments}

To IME and COPPE/UFRJ (Dr. Marcia Sader) for the SEM analyses and Embrapa solos-RJ (Viviane Escaleira) for ICP analyses.

\section{References}

[1] N. C. C. Rocha, R. C. Campos, A. M. Rossi, E. L. Barbosa and G. T. Moure: Environ Sci Technol. Vol. 36 (2002), p. 630.

[2] E. Mavropoulos, A. M. Rossi, A. M. Costa, C. A. C. Perez and J. C. Moreira: Environ Sc.i Technol. Vol. 36 (2002), p. 1625.

[3] M. H. Prado da Silva, S. R. A. Santos, A. M. Rossi: Process for porous interconnected substrate coating synthesis intermediate and obtained porous product. 2007.

[4] M. H. Prado da Silva, J. H. C. Lima, G. A. Soares, C. N. Elias, M. C. de Andrade, S. M. Best and I. R. Gibson: Surface and Coatings Technol. Vol. 137 (2001), p. 270- 276.

[5] Ma QY, Traina SJ, Logan TJ, Ryan, JA: Environ. Sci. Technol. Vol. 27 (1993), p.1803-10.

[6] Chen M, Ma L, Singh PS, Cao R, Melamed R. Advances in Environmental Research; Vol. 8 (2003) p.93-102.

[7] N. C. C. da Rocha, E. Mavropoulos, M. H. Prado da Silva, R. C. de Campos, A. M. Rossi: Key Engineering Materials Vols. 330-332 (2007) p. 123-126. 